\author{
CLARA BARGELLINI \\ INSTITUTO DE INVESTIGACIONES ESTÉTICAS, UNAM
}

\title{
El entablado jesuita de Santa María de Cuevas: sobrevivencia y desarrollo de una tradición
}

\begin{abstract}
La iglesia es buena y bien adornada, así la testera principal con un lienzo muy grande de la Asunción de bellísimo pincel, como también los lados y el techo con pintura al temple muy vistosa y curiosa.
\end{abstract}

JUAN DE GÜENDULÁIN, S.J., I $725^{\text {I }}$

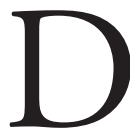
ADO a CONOCER EN un CATÁlogo del Instituto Nacional de Antropología e Historia en $1986,{ }^{2}$ el templo de la antigua misión jesuita de Santa María de Cuevas, Chihuahua (fig. I), fue señalado como particularmente relevante para la historia del arte novohispano algunos años después. ${ }^{3}$ Sin embargo, como es evidente en la breve descripción de 1725 , redactada por un visitador

I. Juan de Güenduláin, Carta al Padre Provincial Joseph de Arjo, Chihuahua, Archivo General de la Nación (en adelante AGN), Archivo Histórico de Hacienda, I8 de mayo de 1725, vol. 2009, exp. 99, f. II.

2. Monumentos Históricos Inmuebles. Chihuahua, México, Insituto Nacional de Antropología e Historia, 1986, vol. III, pp. 787-788.

3. Clara Bargellini, Misiones y presidios de Chihuahua, México, Gobierno del Estado de Chihuahua, 1997, pp. 92-95; "Three Jesuit Churches of the Baja Tarahumara: Jesús Carichí, San Borja, and Santa María de Cuevas", en Transformations on the Mission Frontier: Texas and Northern Mexico, Selected Papers of the I997 Symposium, San Antonio, Texas, Our Lady of the Lake University, 1998, pp. 49-53; “Santa María de Cuevas" en Luisa Elena Alcalá (coord.), Fundaciones jesuiticas en Iberoamérica, Madrid, El Viso, 2002, pp. 372-377. En la actualidad, al lugar 


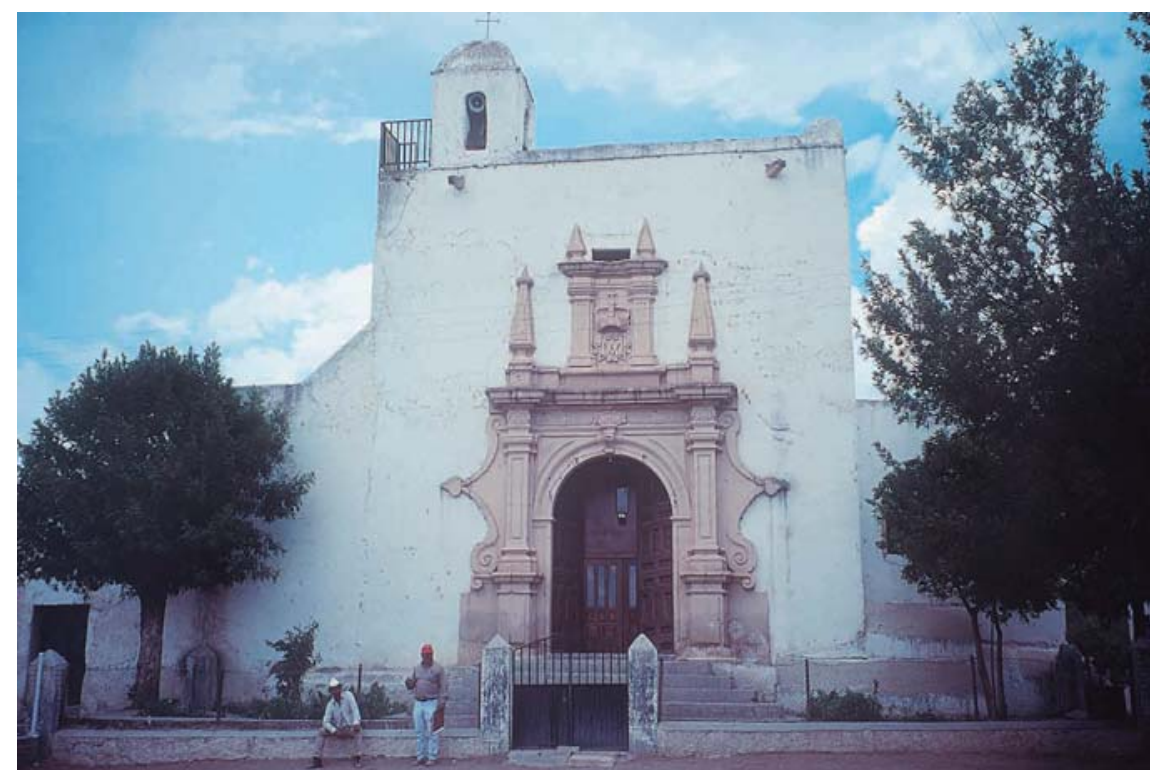

I. Vista general de la fachada, iglesia parroquial, Santa María de Cuevas, Chihuahua. Foto: Libertad Villarreal, 2002.

jesuita y citada arriba, la iglesia siempre ha llamado la atención, en particular por su adorno interior. Se trataba, evidentemente, de un espacio pintado por completo en sus paredes y techo. Había óleos sobre lienzos que hacían las veces de retablos, pintura mural y también un techo figurado, que resulta ser una obra única en su tipo y época, todavía conservada prácticamente completa.

La planta del templo es un rectángulo, aproximadamente de 7.5 metros de ancho y 30 de largo (una simple proporción de I:4), con ábside ochavado. Hoy se conservan en su interior partes de la decoración mural, el techo figurado y un fragmento de uno de los retablos pintados. Los murales que quedan a la vista están en el arco frente al presbiterio (fig. 2), en la pared de arriba del arco del vano que pasa al baptisterio (fig. 3) a la derecha de la entrada a la iglesia, en una cenefa que corre alrededor de todo el edificio inmediatamente debajo del techo (figs. 2, 4, 7) y en partes del baptisterio y de la sacristía. El resto queda recubierto por capas posteriores de pintura. El techo, a pesar de la pérdida de

se le llama generalmente Santa María de Cuevas, pero en documentos novohispanos es frecuente Santa María de las Cuevas. 


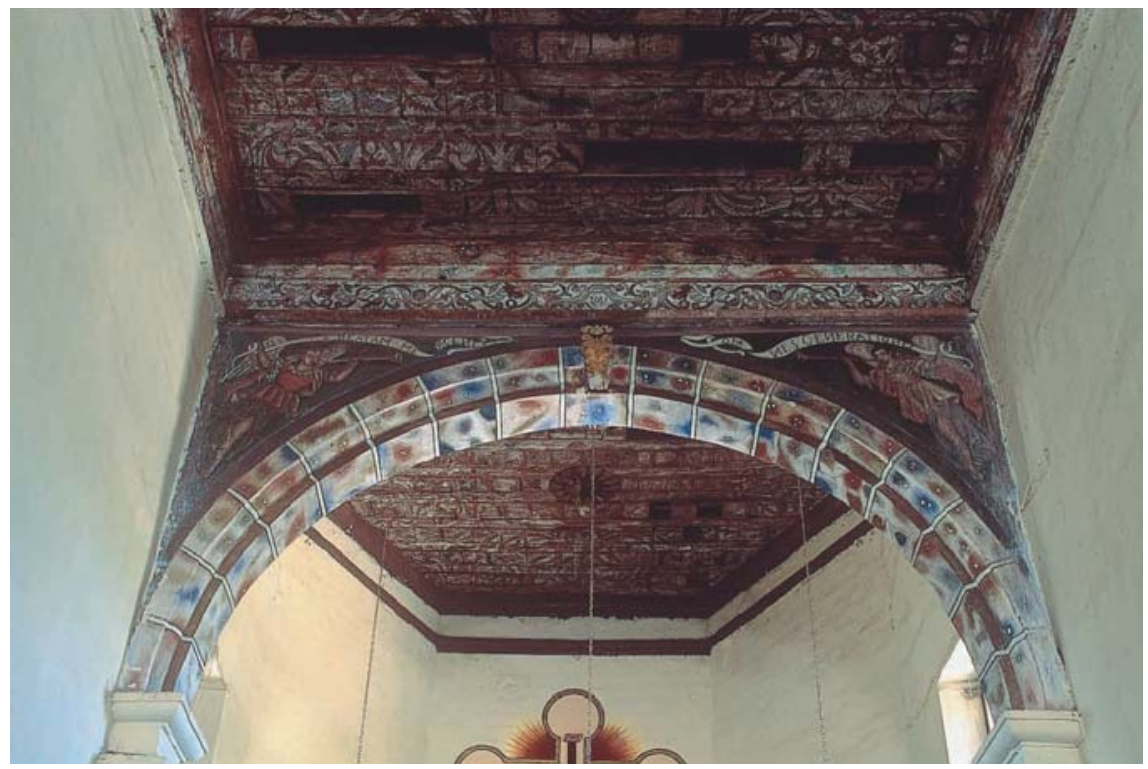

2. Arco triunfal, iglesia parroquial, Santa María de Cuevas, Chihuahua. Foto: Clara Bargellini, 2002.

unas tablas, se ha conservado; está completamente pintado: en la nave (figs. 2 y 4), el presbiterio (fig. 5), el sotocoro (fig. 3), en el baptisterio y en la sacristía. ${ }^{4}$ Es evidente, por las formas y colores de los diseńos, que la pintura de los techos y de las paredes fue pensada al mismo tiempo. Finalmente, ha sobrevivido a los estragos del tiempo la parte central de un retablo pintado, firmado por Juan Correa y dedicado a San Francisco Xavier, registrado como "un cuadro de perspectiva de San Francisco Xavier grande [...] en el cuerpo de la iglesia”, en un inventario de 1753.5

En este ensayo pretendo comprender este espacio jesuita como conjunto, partiendo del análisis de la decoración del techo. Para tal fin, después de una breve descripción y de una revisión sintética del lugar de Santa María en la historia de la arquitectura norteña, buscaré definir la tipología de la decora-

4. La decoración de los muros y techos de estos dos espacios consiste en motivos fitomorfos estilizados y en fragmentos de marmoleado. Los dejo a un lado del análisis que sigue, ya que son espacios subsidiarios y los elementos son similares a los del interior de la iglesia.

5. AGN, Californias, vol. 64, exp. I4, f. 3 IO. 


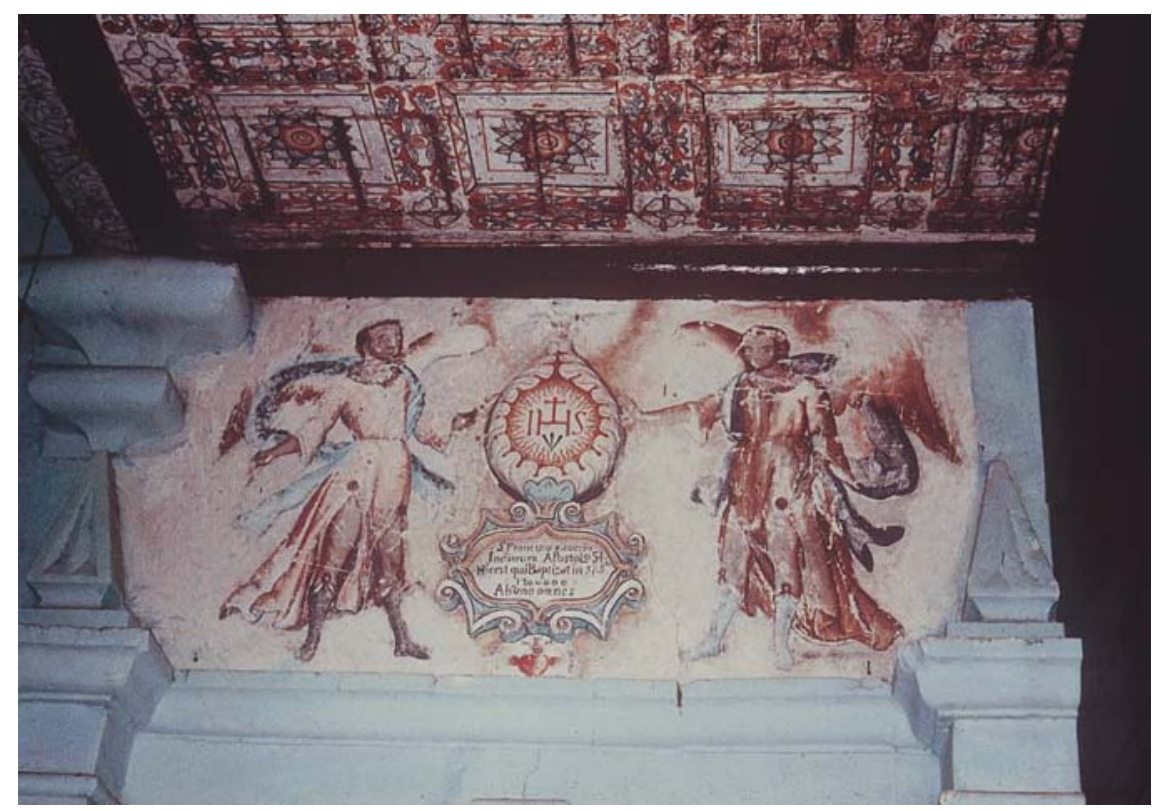

3. Pintura mural arriba de la entrada al baptisterio, iglesia parroquial, Santa María de Cuevas, Chihuahua. Foto: Clara Bargellini, 1997.

ción del techo, para identificar los orígenes y características de las tradiciones estructurales y artísticas en él asimiladas, y explicar cómo se integran sus motivos a un programa que abarca todo el edificio, incluyendo la portada y las pinturas del interior.

\section{La historia y la arquitectura}

Santa María de Cuevas (así llamada, al parecer, por unas cuevas localizadas en las cercanías del poblado) fue mencionada por primera vez en I663, como visita de la misión de San Francisco Xavier Satevó. ${ }^{6}$ Todavía en I 678, los documentos indican que no había iglesia en Cuevas. En ese año, el misionero de

6. Los siguientes datos históricos, a menos que se indique otra cosa, fueron proporcionados por Susan Deeds, "Santa María de Cuevas", ms. inédito, 2003; véase de la misma autora Defiance and Deference in Mexico's Colonial North, Austin, University of Texas Press, 2003, pp. I4O-I 4I. 
4. Entablado de la nave, iglesia parroquial, Santa María de Cuevas, Chihuahua. Foto: Libertad Villarreal, 2002.

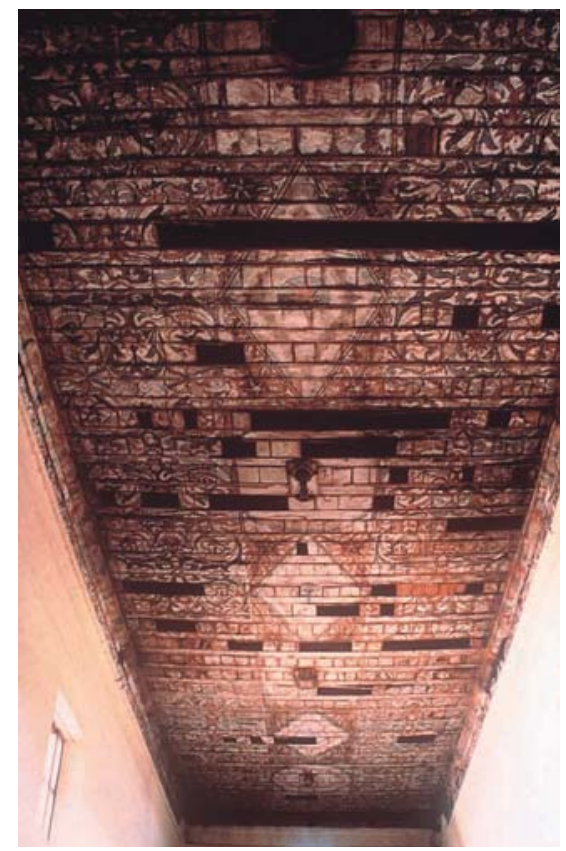

Satevó, Juan Sarmiento, había empezado a corregir esa situación con la construcción de un templo y una casa en Santa María. Sarmiento también estaba reconstruyendo la misión de Satevó. En i 69 I, el padre Domingo Lizarralde, quien estaba entonces de misionero en Satevó, pidió que se dividiera la misión y, en efecto, en I 692 Santa María tenía su propio misionero, Sebastián Pardo, quien también atendía una visita en San Lorenzo (hoy Belisario Domínguez). Según Lizarralde, existía para entonces una iglesia en Santa María de Cuevas. Después de un año, Pardo había sido transferido al Tizonazo y Santa María era de nuevo visita de Satevó. El misionero siciliano Luis (Luigi) Mancuso, quien había estado en la cercana misión de San Francisco de Borja desde I693, llegó a Santa María en I 696, lugar que se hizo cabecera otra vez, con visitas en San Lorenzo y Santa Rosalía. Mancuso estuvo en Cuevas hasta por lo menos I 7 I 8, simultáneamente sirvió como rector y visitador de la provincia jesuita de Tepehuanes y Tarahumara Baja entre I 7 I 4 y I7 I7, y apoyó la fundación del colegio jesuita en Chihuahua. Sus capacidades lo llevaron a ser rector del Colegio Máximo de San Pedro y San Pablo en la ciudad de México, donde residía en I723. Sin embargo, podemos pensar que tenía un particular afecto 
por Santa María, ya que regresó a la misión donde murió en $1728 .{ }^{7}$ El padre Balthasar Peña, quien había estado en Satevó, sucedió a Mancuso en Santa María y allí murió en I 743. Siguió Felipe Calderón, quien se quedó hasta I75 I. Los últimos misioneros de Santa María fueron Felipe Rico y Bernardo Trevińo. Los dos estuvieron muy poco tiempo, ya que la misión estuvo entre las que fueron secularizadas voluntariamente por los jesuitas en 1753 .

Estos datos escuetos sobre la administración de la misión permiten suponer que antes de I69I no hubo una iglesia importante en Santa María. Es probable que haya habido un lugar asignado al culto, y bien pudo ser una construcción menor o un inicio de la construcción que hoy conocemos. Resulta lógico creer que, por el hecho de ser cabecera a partir de I69I, se haya procurado construir o terminar un templo más formal alrededor de esa fecha, que debe haber sido el que estaba, según Lizarralde, en I 692. Bien pudo tratarse del que se había iniciado en 1678 y que, por lo menos en parte, sea el mismo edificio que subsiste hasta la actualidad. Es importante reconocer, sin embargo, que para que Lizarralde dijera en I 692 que había iglesia en Santa María bastaba que existiese un edificio funcionando como tal; no prueba nada acerca de las características materiales precisas de su construcción. De todos modos, se puede sostener la hipótesis de la existencia de una iglesia alrededor de I69I, que podría coincidir con la presente, que es de arquitectura sencilla. Lo seguro es que el edificio actual de Santa María estaba terminado en I700, fecha inscrita en la pared de arriba del arco por el lado del presbiterio, junto con el nombre de "Pintor Domingo Guerra f. año D. $1700 ",{ }^{8}$ muy probablemente el autor de la decoración del techo y de los muros del templo. Los datos históricos también inducen a pensar que el padre Mancuso tuvo un papel relevante posiblemente en la construcción, pero muy probablemente en la decoración.

Para valorar la decoración del interior del templo de Cuevas, hay que agregar que las tres últimas décadas del siglo Xviı fueron cruciales para la historia de la arquitectura en la Nueva Vizcaya, desde Durango hasta Parral, y también para las misiones jesuitas entre los tepehuanos y tarahumaras. Fue en esos años en que las iglesias de una nave, con ábside ochavado, como la de Santa María,

7. Sobre Luis Mancuso véase José Gutiérrez Casillas, Diccionario bio-bibliográfico de la Compañía de Jesús en México, México, Editorial Tradición, 1977, vol. XVI, pp. 97-98.

8. La fecha fue descubierta en mayo de 200I, después de haberse retirado un cielo raso que cubría el techo del presbiterio, durante los estudios técnicos que llevaban a cabo el Instituto Nacional de Antropología e Historia de Chihuahua, Misiones Coloniales de Chihuahua, A.C., y el Instituto Chihuahuense de Cultura en Santa María. 


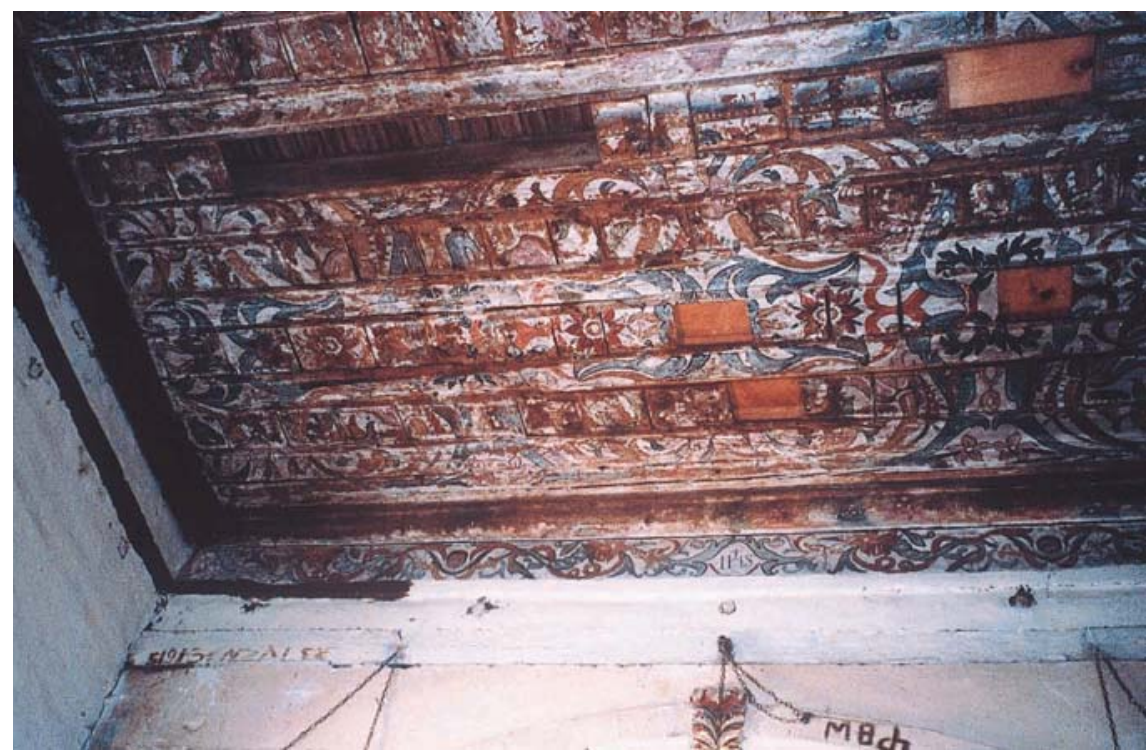

5. Detalle del entablado del presbiterio, iglesia parroquial, Santa María de Cuevas, Chihuahua. Foto: Clara Bargellini, 2002.

o redondeado, y a veces con elevación diferenciada entre la nave y el presbiterio para dar lugar a una ventana que iluminara el altar (el claristorio transversal), 9 empezaron a ser reemplazadas por edificios más complejos. Se introdujeron los cruceros, las plantas de tres naves y las bóvedas, tanto de mampostería como fingidas, de madera. ${ }^{\text {Io }}$ La historia de esta nueva arquitectura en la zona inicia con la llegada al real de San José del Parral del maestro Simón de los Santos,

9. El estudio clásico sobre estos edificios con claristorio transversal es el de George Kubler, The Religious Architecture of New Mexico, Colorado Springs, Taylor Museum, I940, y una nueva edición de la University of New Mexico Press, I99i. En años recientes han habido trabajos arqueológicos en las misiones de Nuevo México que han ampliado mucho nuestros conocimientos sobre este tipo de iglesias: James E. Ivey, In the Midst of a Loneliness: The Architectural History of the Salinas Missions, Santa Fe, New Mexico, National Park Service, 1988.

ı. Clara Bargellini, "La arquitectura y el arte de las misiones: procesos y ejemplos", en $\mathrm{Mi}$ siones para Chihuahua, México, México Desconocido, 2004, pp. I28-I 47; "At the Center on the Frontier: The Jesuit Tarahumara Missions of New Spain”, en Thomas Dacosta Kaufmann, Time and Place: The Geohistory of Art, Londres, Ashgate Press, 2005, pp. I I 3-I34; "Arquitectura jesuita en la Tarahumara: ¿centro o periferia?”, en Órdenes religiosas entre América y Asia. Ideas para una historia misionera de los espacios coloniales, México, El Colegio de México (en prensa). 
"que lo es en la facultad de arquitectura", desde la ciudad de México, entre I672 y I 678. ${ }^{\text {II }}$ De los Santos estuvo en Parral por lo menos hasta I686, según la última fecha inscrita en la antigua parroquia de San José, su obra principal en el real de minas, que es la iglesia con bóvedas más antigua que se conserva actualmente en todo el vasto territorio que fue la Nueva Vizcaya.

Sin embargo, la nueva arquitectura no sustituyó del todo a la antigua. Más aún, probablemente la enriqueció de manera particular en los aspectos que interesan para Santa María de Cuevas: los conocimientos especializados de carpintería y la pintura mural. Conviene recordar que los jesuitas eran muy conocidos en Parral, ya que habían tenido misiones en la región desde la primera década del siglo XVII. La fundación de un colegio en I 684, con una pequeña iglesia adjunta que medía 22 por 9 varas, y que tenía "techo de madera", fue la culminación de su presencia en el real de minas. El apoyo para realizar esta obra vino de Luis de Simois, sobrino de uno de los patronos de la parroquia. Aunque nada de la arquitectura del colegio y de la iglesia jesuita de Parral parecería haber necesitado de los particulares conocimientos de Simón de los Santos, el arquitecto trabajó para los jesuitas en la misión de Nombre de Jesús en Carichí, donde se encontraba cuando fue llamado a la obra de la catedral de Durango, en I698. En I 725 el padre Güenduláin escribió acerca de Carichí:

La iglesia es la mejor de esta Provincia, de tres naves en la forma que estaba la Profesa antigua. Las maderas del artesón bien labradas y curiosamente pintadas. Los pilares son unos pinos de una pieza, de cuerpo tan grueso y tan bien labrados y pintados que a la primera vista parecen de piedra o de ladrillo. ${ }^{\mathrm{I2}}$

Ha desaparecido la pintura original en su interior, pero la iglesia de Carichí con sus columnas de troncos de pino existe todavía (fig. 6). Parece que De los Santos y probablemente algunos maestros u oficiales que trabajaban con él utilizaron en Carichí algunos de los mismos recursos de carpintería y pintura que vemos en Cuevas y en otras misiones. Hay que concluir que la construcción de Santa María de Cuevas, probablemente llevada a cabo entre i 678 y I 692, pese a tener un tipo relativamente sencillo en su estructura fundamental, se inserta en una historia de ambiciones arquitectónicas de los jesuitas en la región hacia

I . Clara Bargellini, La arquitectura de la plata, México/Madrid,Universidad Nacional Autónoma de México/Turner, I99I, pp. 218-220, de donde provienen los datos que siguen en el texto sobre Simón de los Santos, Parral y Durango.

I2. AGN, Historia, 20, exp. 3, f. $3 \mathrm{v}$. 
6. Interior de la iglesia de Nombre de Jesús, Carichí, Chihuahua. Foto: Libertad Villarreal, 2002.

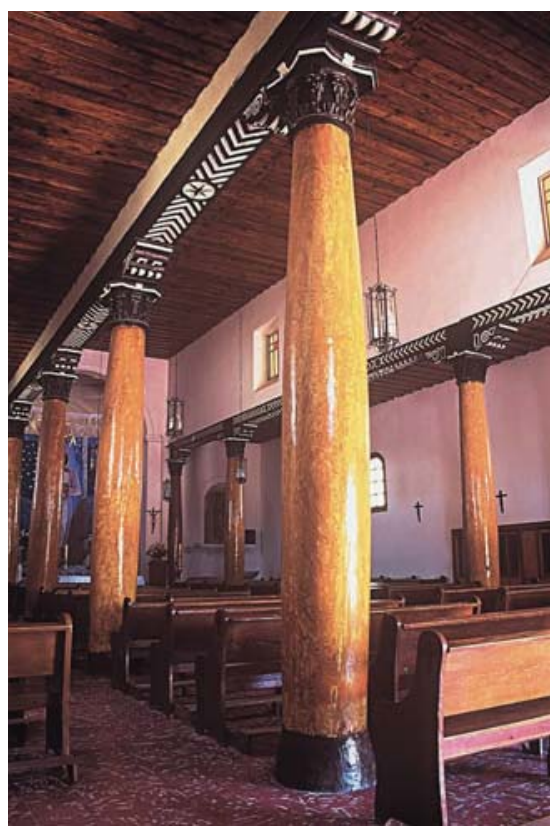

finales del siglo xviI. En Cuevas estos anhelos se concentraron en el adorno del templo de la misión, emprendido en los años posteriores a su construcción.

\section{El entablado de Santa María de Cuevas}

Ya que el techo pintado de Santa María es el elemento más sobresaliente de lo que queda de la decoración interior de la iglesia, el resto de este ensayo se concentrará en encontrarle un lugar dentro de la historia del arte. Por ser el único ejemplo en su tipo que se conserva, la tarea no es sencilla. Empecemos por sus características físicas. Se trata de un alfarje de un solo orden de vigas. A su vez, éstas tienen ranuras continuas en sus bordes inferiores, dentro de las cuales se acomodan tabletas en sentido perpendicular a la dirección de las vigas. Unos listones largos ("saetinos") ${ }^{13}$ ayudan a sostener las tabletas y cubren las ranuras

13. Enrique Nuere, La carpintería de armar española, Madrid, Ministerio de Cultura, I989, Léxico, ad vocem. Agradezco las indicaciones sobre éste y otros puntos técnicos e históricos a los colegas Rafael López Guzmán y Humberto Rodríguez Camilloni. 
entre ellas y las vigas (figs. 2, 4, 5, 7). Estas tabletas, las caras inferiores de las vigas y los listones, en conjunto, conforman una superficie casi plana, que se puede denominar "entablado". ${ }^{14}$ El entablado de Santa María se integra a la estructura portante del techo, que son las vigas, pero es claro que se trataba de proporcionar un campo lo más libre posible para que se pudiera desarrollar allí un programa pictórico. Más aún, parece que se anticipó esta finalidad desde la propia construcción del techo.

En un primer momento, la existencia de un gran número de artesones de madera pintados en Michoacán ${ }^{\mathrm{I} 5}$ me llevó a pensar que pudo haber una relación estrecha entre estas obras y la de Santa María. Se tienen, además, numerosas noticias de presencia michoacana en la población del centro-norte, así como de nexos comerciales. ${ }^{16} \mathrm{~A}$ pesar de todas estas relaciones, el estudio y la observación más cuidadosa de algunos casos aconsejan reformular esta hipótesis, porque los artesones pintados que hoy se conservan en Michoacán no son parte integral de las techumbres como en Santa María. Más aún, el entablado de Cuevas es más antiguo que prácticamente todos los techos michoacanos que se conservan. Por lo pronto, y reconociendo la necesidad de ulteriores estudios tanto en Michoacán como en Chihuahua, podemos seguir pensando que los techos michoacanos son importantes para Santa María, como referencia y comparación, pero no necesariamente como origen directo de una tradición artesanal. ${ }^{17}$ Más bien, el origen de lo que se hizo tanto en la Tarahumara como en Michoacán estaría en una tradición aún más antigua.

A pesar de que el techo de Santa María es el ejemplo más antiguo que conozco hasta el momento en México con su particular forma de construcción y decoración, no cabe de ninguna manera afirmar que haya sido ni el primero ni el único. En el siglo Xvir hubo en toda la Nueva España un proceso general de sustitución de techos de madera por cubiertas de bóveda, y en el siglo xx la sus-

I 4. Debo esta atinada sugerencia, basada en un léxico histórico, a Gloria A. Álvarez Rodríguez y a Alfonso Pacheco Hernández.

I5. Gloria A. Álvarez Rodríguez, Los artesones michoacanos, Morelia, Gobierno del Estado de Michoacán, 2000. Véase también Rafael López Guzmán, Arquitectura y carpintería mudéjar en Nueva España, México, Azabache, 1992.

I6. Chantal Cramaussel, "Relaciones entre la Nueva Vizcaya y la provincia de Michoacán", Relaciones, vol. 24, 100, otoño 2004, pp. 173-203.

I7. Quiero agradecer la generosidad y paciencia de Gloria A. Álvarez Rodríguez y Alfonso Pacheco Hernández, quienes me proporcionaron información sobre techos michoacanos poco conocidos y me dieron sus opiniones sobre estos problemas. 


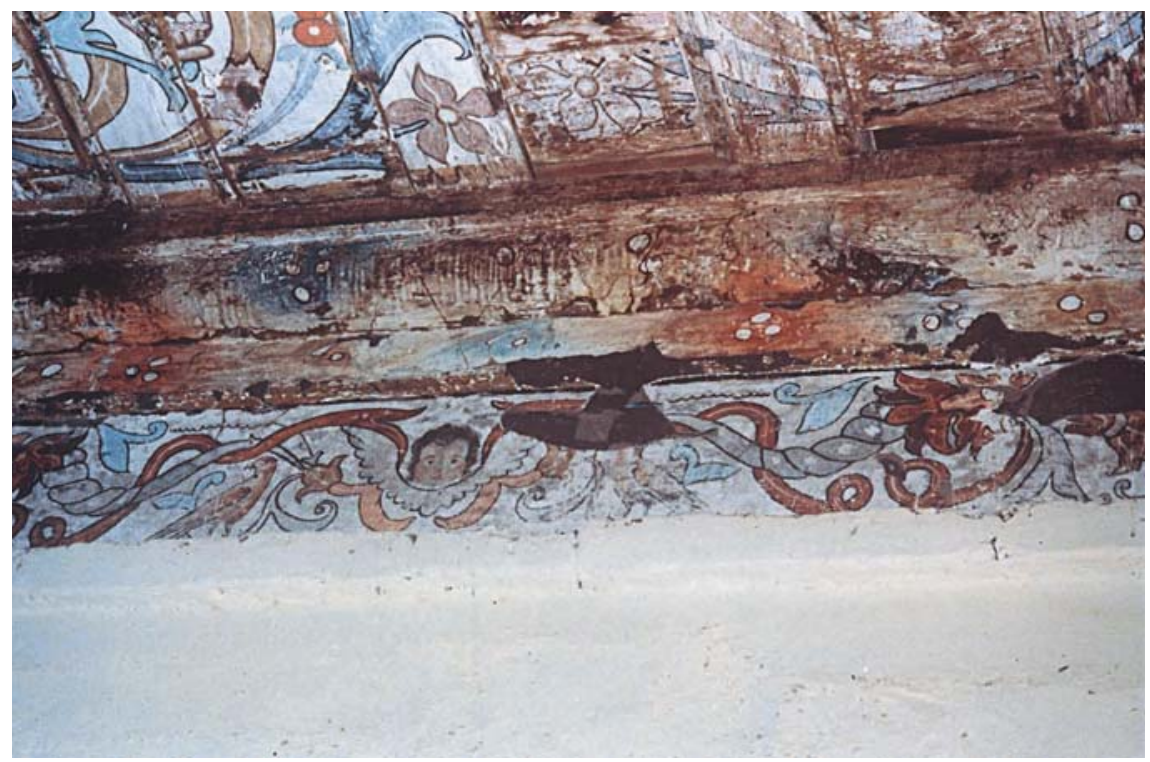

7. Detalle de la cenefa de la nave, iglesia parroquial, Santa María de Cuevas, Chihuahua. Foto: Clara Bargellini, 2002.

titución de techos de vigas por cemento o estructuras metálicas con aluminio ha sido desastrosa para la historia de la arquitectura. Los techos de madera son muy pocos con relación a los que hubo, y están muy alterados en muchos casos, así que hemos perdido una gran cantidad de obras que podrían haber sido los antecedentes directos del techo pintado de Santa María. Por lo pronto, sin embargo, los únicos techos con este sistema de construcción que conozco en México están en la Baja Tarahumara, en las iglesias de las exmisiones jesuitas de Cuevas y en la sección central de la nave de Santa Cruz (hoy Rosario) (fig. 8). Es posible que el techo "curiosamente pintado" de Carichí haya sido del mismo tipo. Estos techos - y los otros que están mencionados en documentos, o que se conservan muy parcialmente—, ${ }^{18}$ confirman la importancia del entablado de Santa María, aunque no ayudan a rastrear sus orígenes en otras regiones.

Al no encontrar construcciones parecidas a la de Cuevas en otros techos novohispanos, amplié la búsqueda al resto de Latinoamérica. Existen muchos entablados en Sudamérica, pero casi no he encontrado estudios técni- 
cos publicados, y hasta ahora ningún entablado del tipo del de Santa María. ${ }^{19}$ También he buscado posibles antecedentes europeos. ${ }^{20}$ Cabe señalar que, en la arquitectura eclesiástica europea de la época moderna, el techo plano es muy propio del Renacimiento, retomando la arquitectura clásica antigua. En efecto, abundan los techos planos en los siglos XV, XVI y XVII, generalmente decorados con casetones, y muchas veces con marcos y figuras en pintura y en relieve, en todos los lugares de Europa que tuvieron algún impacto en las tradiciones artísticas novohispanas y americanas en general: España, Portugal, Italia y Flandes (Bélgica). Se conservan también en ámbitos domésticos en Escocia. Sin embargo, los estudios histórico-artísticos sobre estos techos son pocos y se han enfocado más a la iconografía que a los métodos de construcción y a las características estructurales. Por otra parte, existen investigaciones técnicas sobre cubiertas medievales de tipo gótico o mudéjar, pero muy pocas sobre techos planos, a pesar de obras tan sobresalientes como, por ejemplo, los entablados medievales de la catedral de Peterborough, en Gran Bretaña, de San Miguel en Hildesheim, Alemania, y de Zillis, en Suiza. Una posible dirección para la investigación futura podría ser el estudio de los techos de los espacios domésticos y civiles, por la sencillez de la arquitectura del templo de Cuevas. ${ }^{21}$ De todos modos, la búsqueda de materiales comparativos debe seguir, ya que la pregunta acerca de la filiación del entablado de Santa María de Cuevas no puede considerarse cerrada.

\section{El diseño del entablado}

Mientras tanto, sin embargo, podemos avanzar por otro camino: el del diseño de la decoración del entablado de Santa María. Se pueden agrupar en tres tipos las distintas maneras en que se relacionaron los diseños de las cubiertas con la arquitectura en la Nueva España. Uno es el diseńo que repite el mismo motivo, sin poner atención particular en la forma o dimensión del espacio a cubrir. Por lo general, los diseños de estos techos son geométricos y derivan

I9. Para un estudio detallado de un entablado en Tunja, véase Pilar Jaramillo de Zuleta, Coro alto de Santa Clara, Bogotá, El Navegante Editores, I991.

20. Para esta búsqueda, además de la ayuda de los colegas mencionados en notas anteriores, agradezco las sugerencias de Patricia Díaz Cayeros y María Feliciano.

2I. En este sentido son muy interesantes los techos escoceses: M. R. Apted, The Painted Ceilings of Scotland, I5 50-1650, Edimburgo, Her Majesty's Stationary Office, I996. 


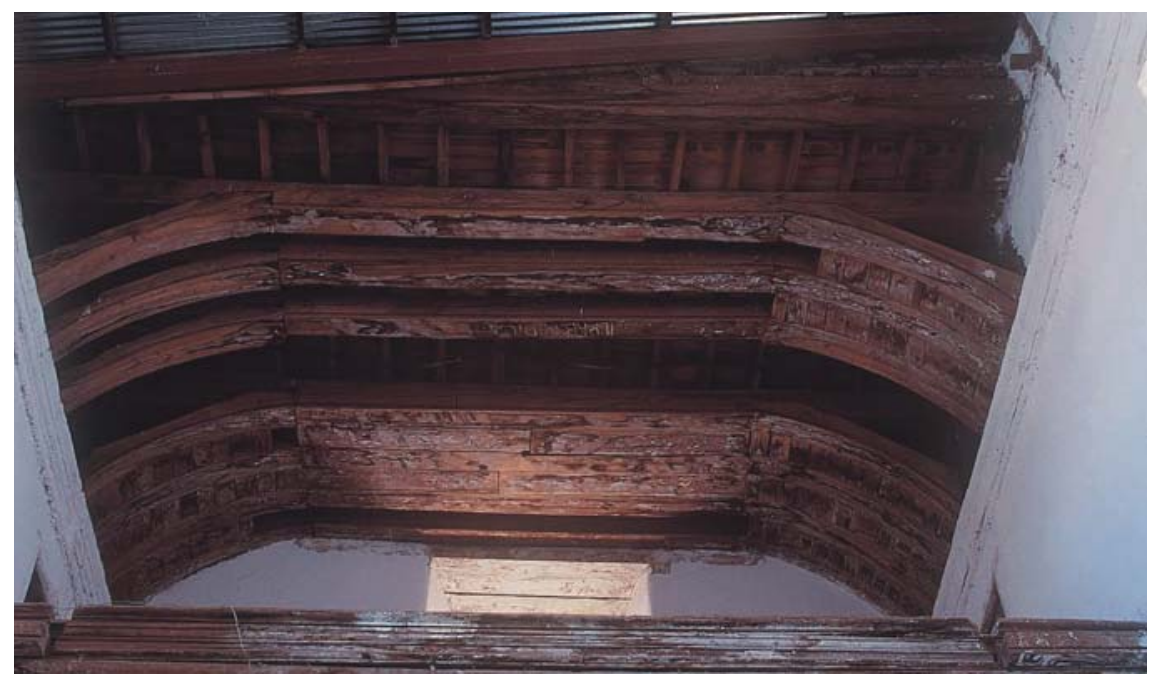

8. Entablado de la iglesia de Santa Cruz (Rosario), Chihuahua. Foto: Libertad Villarreal, 2000.

de modelos del tratado de arquitectura del siglo xvi de Sebastián Serlio. La definición del espacio se da generalmente por elementos que enmarcan y, por lo tanto, delimitan y contienen los motivos repetitivos de la decoración del techo. Fue muy frecuente este tipo de decoración en los espacios conventuales del siglo XVI (fig. 9).

El segundo tipo de diseño consiste en motivos variados, a menudo curvilíneos y hasta con figuras, pero todo en relación con las divisiones de los espacios específicos de la arquitectura. Pueden variar los elementos en cada tramo, pero se marcan los extremos, los centros y las divisiones entre un espacio y otro. A diferencia del primer tipo, que puede extenderse en todas las direcciones, este diseño ayuda a percibir el espacio con precisión, midiéndolo. Tal vez el espacio paradigmático de este tipo de entablado es la Biblioteca Mediceo Laurenziana de Florencia, diseñada por Miguel Ángel. ${ }^{22}$ Allí, los motivos del techo y del piso se reflejan, y la articulación de las paredes los relaciona con precisión: el espectador puede percibir en este tipo de interior, viendo el techo o la bóveda, las dimensiones del espacio en términos de módulos, y, en el caso de la

22. Maria Ida Catalano, Il Pavimento della Biblioteca Mediceo Laurenziana, Florencia, Cantini, 1992. 
nave de una iglesia, se siente invitado a seguir una secuencia a lo largo de un eje longitudinal, marcado por los motivos centrales de la cubierta, a menudo diferenciados entre sí. Este tipo de decoración de techos es el que más se ha conservado en México. Lo tenemos en los conventos e iglesias del siglo XVI, como por ejemplo en la bóveda del coro de la iglesia de Tlayacapan, y existen muchos otros del siglo XVII, como en la capilla doméstica del noviciado jesuita de Tepotzotlán, la capilla del Rosario, y en la iglesia de Santo Domingo de Puebla, para citar algunos casos muy conocidos.

El tercer tipo de diseño fue introducido a la Nueva España de manera contundente por el pintor Cristóbal de Villalpando en la capilla de los Reyes de la catedral de Puebla en I689. ${ }^{23}$ Tratándose de la apropiación de un espacio arquitectónico por un pintor, los elementos de la decoración son en su mayoría figurativos. Aunque la composición está anclada por unos sencillos motivos arquitectónicos pintados alrededor de la franja inferior de la cúpula para sugerir que está dividida en ocho secciones, lo que se busca es crear una ilusión que rompa los límites de la arquitectura. Las figuras ocupan un espacio que quiere representar el cielo en su infinitud. Este tipo de decoración, cuyos orígenes están en el Renacimiento italiano, tuvo acogida en toda Europa en el siglo XVII. Generalmente, como también sucedió en la Nueva España, se encuentra en cúpulas y en bóvedas, y tuvo también un desarrollo importante en el siglo XviII. En Portugal y Brasil se desarrolló a menudo sobre entablados en diseños que buscan crear la ilusión de grandes espacios. ${ }^{24}$ A diferencia de los otros dos tipos de diseño, esta decoración apela a la contemplación desde posiciones precisas. No invita al movimiento unívoco y ordenado a lo largo de un eje, ni mucho menos a la medición racional del espacio, ya que lo que se experimenta es lo contrario. No está por demás recordar que entre los principales promotores de este tipo de decoración en Europa se encontraban los jesuitas, especialmente a través de las obras de Andrea Pozzo. ${ }^{25}$

23. Juana Gutiérrez Haces (coord.), Cristóbal de Villalpando, México, Fomento Cultural Banamex/Universidad Nacional Autónoma de México-Instituto de Investigaciones Estéticas/Consejo Nacional para la Cultura y las Artes/Grupo Modelo, 1997, pp. 218-22 I.

24. Magno Moraes Mello, A pintura de tectos em perspectiva no Portugal de D. Joao V, Lisboa, Editorial Estampa, 1998.

25. Robert England, The Baroque Ceiling Paintings in the Churches of Rome, I600-1750, Hildesheim/Nueva York, Olms, I979; Juergen Schulz, Venetian Painted Ceilings of the Renaissance, Berkeley/Los Angeles, University of California Press, I968; Ingrid Sjöström, Quadratura. Studies in Italian Ceiling Painting, Estocolmo, University of Sockholm, 1978. 
9. Corredor del convento de la Natividad de la Virgen, Tepoztlán, Morelos. Foto: Clara Bargellini, I995.

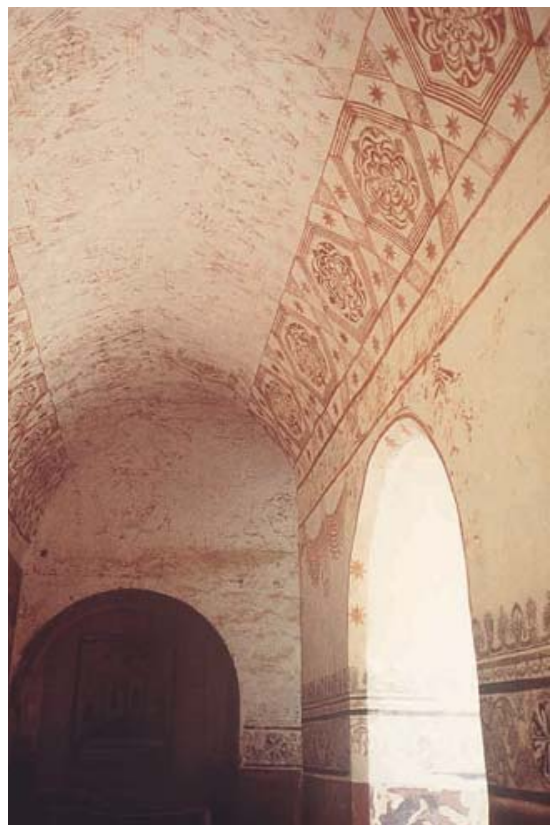

Después de este recorrido, es evidente que en Santa María de Cuevas tenemos diseños de cubiertas principalmente del primero y del segundo tipos. En el sotocoro (fig. 3) encontramos el primer tipo de decoración, en la que los motivos se repiten para cubrir la extensión del techo. Vemos casetones clásicos, parecidos a los del libro IV del tratado de Serlio. En la nave y en el presbiterio (figs. 2, 4, 5), por otra parte, observamos más bien el segundo tipo de diseño, aunque con resabios del primero, así como atisbos del tercero, como veremos más adelante. Los cuadrados y rombos, con símbolos marianos al centro, proporcionan un eje longitudinal de acuerdo al espacio arquitectónico. Tanto estos elementos como el módulo de motivos florales que se repite a ambos lados son suficientemente grandes como para ser legibles desde abajo y proporcionan un sentido de medición del espacio. Nótese que en Santa María esta medición está impuesta desde el techo, ya que es difícil hablar de tramos al interior de un templo de planta tan sencilla y sin conocer la decoración original completa de los muros laterales. No hay que soslayar que los motivos florales del entablado no exhiben una relación precisa con los cuadrados y rombos del centro. Funcionan más como marco de los elementos centrales, o también como fondo, que como parte de un sistema de medición integrada. Abona 
esta impresión el hecho de que las dimensiones de los módulos florales no coinciden con los límites del espacio real del entablado. En los dos extremos de la nave (fig. 2), el pintor tuvo que añadir elementos para llenar la superficie de la cubierta. Estas irregularidades hacen pensar en los diseños repetitivos y sin límites fijos del primer tipo de decoración de techos.

Como en el primer tipo de diseño, en el entablado de Cuevas también se trata en gran parte de motivos de raigambre clásica difundidos por Serlio, entre otros. En los dibujos de techos que el tratadista propone como modelos, señalando que conviene que los fondos sean de color claro — recomendación seguida en Santa María—, se ven motivos estilizados de hojas, flores y animales, en esquemas de movimiento regular y rítmico, que son del tipo de los que aparecen en Cuevas. Serlio tomó estos motivos vegetales y florales de monumentos romanos, pero fueron aceptados con entusiasmo en el arte cristiano desde las catacumbas hasta prácticamente nuestros días, por su asociación con la idea de la belleza y del florecimiento que acompañan el concepto de paraíso y la abundancia de la gracia divina presente en la iglesia, tanto en la institución como en sus representaciones en arquitectura. Los ejemplos son incontables y se encuentran en paredes, techos y bóvedas, desde el Mausoleo de Galla Placidia, en Ravenna, hasta la iglesia Palatina de Carlomagno, en Aquisgrán, y los ábsides de San Clemente y Santa María Maggiore, en Roma, por mencionar sólo algunos ejemplos medievales muy conocidos. Los mismos motivos aparecen también en textiles utilizados en vestuario litúrgico, en vasos sagrados y en la decoración de páginas de libros. En pocas palabras, los senderos por los cuales estos motivos vegetales y florales pueden haber llegado a Santa María son muchos, pero con esto no se invalida el resultado fundamental de nuestra búsqueda de los orígenes artísticos del entablado de Santa María por el camino de la tipología. Se trata de maneras renacentistas de concebir el diseńo de la ornamentación del espacio y de motivos de raigambre clásica, igualmente renacentistas.

Un elemento en particular de la decoración de Cuevas confirma esta conclusión. Hay que notar que los motivos de las flores, hojas y guías rebasan el entablado para correr también por toda la cenefa pintada en la pared inmediatamente debajo del cielo de la nave. Se trata de un solo motivo repetido muchas veces: una guía, en forma de $S$ alargada, de hojas y flores estilizadas, que se extiende simétricamente a ambos lados de una cabecilla de angelito enmarcada por dos aves (fig. 7). Se trata de esquematizaciones de formas naturales dentro de un diseño regular y de un realismo delicado aunque repetitivo en la representación de los angelitos y de las aves. La pintura de la cenefa — se trata aquí 


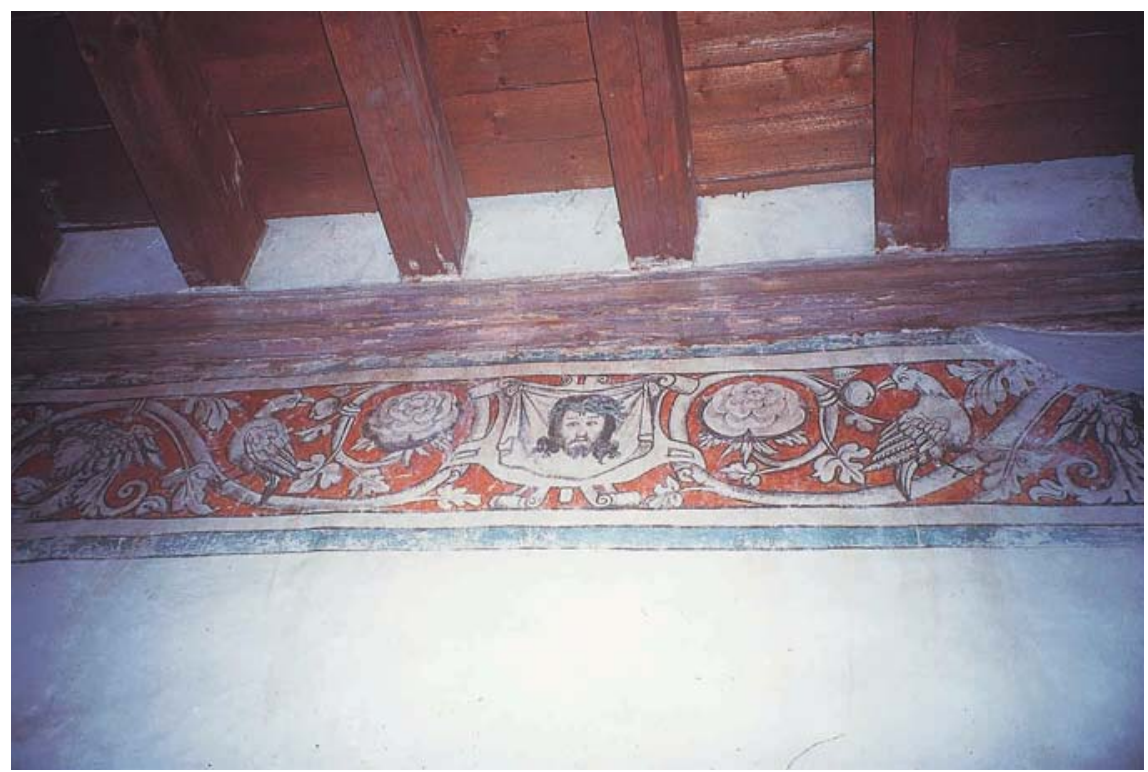

ı o. Cenefa de un corredor del convento de San Martín, Huaquechula, Puebla. Foto: Clara Bargellini, I995.

de las paredes, ya no del entablado propiamente — es de buena calidad, como puede verse en la sutileza del colorido y en las variaciones en las cabecillas. Este esquema, de un elemento sagrado al centro y guías a los lados, está presente no sólo en Santa María, sino también en muchísimos metros de cenefas pintadas en conventos e iglesias novohispanas del siglo xvi. Hay casos parecidos a la cenefa de Santa María en los fragmentos recién encontrados en Tlatelolco ${ }^{26}$ y en el convento franciscano de Huaquechula, por ejemplo (fig. Io). En algunas cenefas del siglo XVI se ven las mismas guías en forma de cornucopias que podemos observar en Cuevas, las aves simétricas y las cabecillas de angelitos. Hay que subrayar que en Santa María ha desaparecido cualquier rasgo grutesco del tipo que está presente en Serlio y en algunos conventos; vemos más bien motivos renacentistas depurados y cristianizados, como es de esperar en obras posteriores al Concilio de Trento.

En síntesis, la ornamentación arquitectónica de Santa María nos remite con toda claridad a tradiciones de diseño y de iconografía renacentistas, adoptadas 
en el siglo Xvi en la Nueva Espańa. Esta conclusión sugiere que para entender el entablado de Cuevas debemos tomar en cuenta la extensa tradición de pintura mural desarrollada durante el siglo XVI, especialmente en los pueblos indígenas del Altiplano Central. Esta tradición no tiene por qué haber desaparecido del todo después de I 600, aunque la historia del arte así lo ha considerado hasta ahora en la práctica. El diseño, las formas y la calidad de la pintura de Santa María obligan más bien a pensar en un artista entrenado en una sólida y larga tradición de decoración arquitectónica, como sería justamente la de la pintura mural de los conventos del siglo xvi y su continuación en el siglo XviI. Esta hipótesis proporciona nuevas pistas para el examen del entablado de Santa María e identifica esta iglesia como una prueba relevante de la supervivencia y el desarrollo hasta por lo menos i 700 de una tradición que nació en los albores del arte novohispano.

\section{La iconografía de la iglesia y de su decoración}

Pese a que el techo de Cuevas nos remite en buena parte a modelos muy anteriores a I 700, en los cuadros y rombos centrales de la nave con sus símbolos sobre fondos de nubes, debemos reconocer una concesión a la ilusión de formas y espacios, análoga — toda proporción guardada — a la que plasmó Villalpando en la cúpula de Puebla. Los símbolos de la nave flotan entre nubes que rompen, por lo menos conceptualmente, el plano del entablado. Son, además, sólo parte de un bien desarrollado programa iconográfico que debe leerse en conjunto para entenderse cabalmente. Resulta ser un programa que confirma los orígenes renacentistas de la tradición pictórica desplegada en Santa María.

La iglesia está dedicada a la Asunción de la Virgen; es decir, su entrada al cielo en cuerpo y alma, llevada por los ángeles. El evento está asociado, por cronología, al último episodio de las narraciones marianas: su coronación como reina del cielo. En efecto, en la portada de la iglesia está María, representada por su monograma, coronada (fig. I). Este relieve anticipa el tono de la iconografía que uno debe esperar encontrar adentro de la iglesia: la celebración de la Virgen María, reina del cielo. En efecto, en la nave (fig. 4), en los ocho cuadros y rombos del eje longitudinal del entablado están representados símbolos que aluden a títulos honoríficos de la Virgen (leyendo la secuencia desde el presbiterio hacia el coro): el sol, la luna, una estrella, un espejo, una azucena, una fuente, un rosal y un ciprés. 
El papel sobresaliente de la Virgen en la historia de la salvación es una tradición muy antigua en la Iglesia Católica cuyos puntos más relevantes pueden sintetizarse en pocas líneas. Una de las claves de su desarrollo fue la decisión del Concilio de Efeso en 43 I en el sentido de que María podía llamarse Madre de Dios (Theotokos). De allí se difundió el culto y la iconografía de la Virgen con el Niño Jesús que fue, por mucho, la representación más frecuente de María durante toda la larga Edad Media. Como madre de Dios, María tiene una comprensión completa de la misión salvadora de su hijo. Así, fue afirmándose la idea de que era corredentora de la humanidad. Este papel de casi igualdad con Jesús era acompañado por un deslizamiento de la figura de madre hacia la de esposa. Y como esposa de Jesús, María representa la iglesia que él prometió acompañar siempre. Un resultado de estas ideas sobre la Virgen que tuvo un impacto fundamental en las artes plásticas fue la necesidad creciente de representar sola a la figura de María; no con Jesús o en una escena narrativa, sino sola, como objeto de devoción. De todos los episodios de la vida de la Virgen que se conocían en la Edad Media tardía, el que más fácilmente permitía la representación de su figura aislada era la Asunción: María llevada al cielo por los ángeles. Por lo tanto, hubo un aumento relevante en las imágenes de la Asunción a partir de entonces. En este episodio, María podía presentarse ante los ojos de los fieles como figura de culto independiente de su hijo y de otros personajes o elementos. Si acaso, además de los ángeles que la acompañan, estarían los apóstoles, maravillados ante el milagro de la Asunción, a quienes los fieles deben imitar en alabar y venerar a María.

Así las cosas, hacia principios del siglo XVI se dio un desarrollo iconográfico ulterior con particular fuerza en España: la invención de otra imagen en la que la Virgen aparece sola, rodeada por elementos simbólicos inspirados en el Cantar de los cantares de la Biblia. ${ }^{27}$ Desde entonces esta imagen fue identificada como la Inmaculada Concepción, pero también se le llama la Tota pulchra, justamente por las palabras del Cantar de los cantares (4:7) y para distinguirla de la imagen que ahora consideramos típica de la Inmaculada española, que se conformó un poco más tarde. Desde el primer momento fueron frecuentes en las representaciones de la Inmaculada elementos que pertenecen propiamente a la historia de la Asunción y llegada al cielo de María. Por ejemplo, se retrataba a la Virgen de la Inmaculada, con las manos juntas, rodeada por símbolos

27. Suzanne Stratton, La Inmaculada Concepción en el arte español, Madrid, Fundación Universitaria Espańola, 1989, cap. 2. 
inspirados en el Cantar de los cantares, y al mismo tiempo coronada por la Trinidad. Parece que se querían concentrar en una sola imagen de esta mujer portentosa todos los motivos principales de la gloria de María. Además, muy pronto se agregaron a María Inmaculada, asunta y coronada en el cielo, rodeada de símbolos, algunos elementos de la visión relatada por san Juan. La mujer del Apocalipsis, salvada del dragón, se había identificado desde mucho tiempo atrás con la Iglesia salvada del demonio. Ya que a María se le identifica con la Iglesia, no fue difícil integrar también esta imagen a las representaciones de la Inmaculada. Eventualmente, la Tota pulchra del siglo Xvi fue transformada en la Inmaculada clásica del arte español y novohispano del siglo xviI. Es la mujer en el cielo, resplandeciente como el sol, parada sobre la luna, con una corona de estrellas, con unos símbolos a su alrededor, y a veces con el demonio bajo los pies.

Después de este apretado recorrido iconográfico, debería ser evidente que la representación que tenemos en Cuevas corresponde a la primera etapa de la iconografía inmaculista, la de la Tota pulchra del siglo xvi que integra la Asunción, pero menos a la mujer del Apocalipsis. Esta conclusión nos ayuda a entender todos los elementos y su lugar en la arquitectura de Santa María. Empecemos con el inicio de la letanía, que es el sol en el presbiterio. María es bella o brillante como el sol. ¿Qué quiere decir esto? La pista está arriba del arco frente al presbiterio. Desde la época paleocristiana este arco fue asociado con el triunfo de Cristo sobre la muerte y, por lo tanto, se le llama arco triunfal. Es totalmente apropiada la presencia de Cristo en su monograma (IHS) sobre el arco del lado de su espacio, el presbiterio (fig. 5), arriba del altar donde se hace presente en la Eucaristía. Además, Cristo es el sol al que se equipara María en las letanías. Antes de ser una metáfora para María, en la tradición cristiana el sol es una metáfora para Cristo. Entonces, cuando se dice que María es como el sol, lo que se está afirmando es que María es como Cristo, corredentora. Por eso, todas las letanías inician con la metáfora del sol; es decir, con el concepto de la unidad y casi paridad de María y Jesús.

Pero el arco tiene dos lados, y por el lado de la nave — detrás de donde está el monograma de Jesús - está el monograma de María, coronado como en la portada (fig. 2). María, indisolublemente unida a Jesús en las piedras del arco, está del lado que corresponde al espacio arquitectónico ocupado por los fieles, es decir, la humanidad cristiana, en contraste con el presbiterio, que es el espacio de la divinidad y del sacerdote. Las pinturas de los ángeles en las enjutas que se ven desde la nave explican el lugar de María en la cumbre del arco triunfal. 
Llevan filacterias con una inscripción dividida en dos: beatam me dicent / omnes generationes (todas las generaciones futuras me llamarán bendita). Son palabras que vienen del Magnificat, la oración que dijo María cuando, ya encinta, visitó a su prima Isabel, y ésta reconoció al Salvador, que todavía estaba por nacer. El evento, nominado la Visitación, tiene importancia teológica en cuanto a que fue la primera manifestación de la presencia de Jesús como ser humano, aunque aún estaba en el vientre de María. Con esta inscripción, María se presenta a los fieles reunidos en el templo de Cuevas como humana, pero digna de ser glorificada por toda la historia futura por ser la madre de Dios.

Con estas lecturas del presbiterio y del arco triunfal tenemos elementos suficientes para plantear los conceptos que se desarrollaban en la decoración de toda la iglesia. En síntesis, María estaba presente en el presbiterio tanto en una pintura como en una escultura de la Asunción, que representa el glorioso final de su vida humana y el inicio de su reino en el cielo. En el techo, el sol recuerda su identidad con Cristo-Dios desde siempre y para siempre. Es el espacio de mayor densidad teológica. En el arco triunfal las referencias son a la Encarnación de Cristo como hombre y a la alabanza debida a María, por ser su madre. En la nave se recuerdan frases del Cantar de los cantares y de varios textos piadosos: bella como la luna, estrella del mar (o estrella matutina), espejo sin mancha, azucena entre espinas, fuente de salvación, rosa sin espinas, ciprés en Sión. Los símbolos son algunos de los más representados en las composiciones de la Tota pulchra del siglo Xvi. Como María asunta, a la que representan en este caso, los símbolos están en el cielo entre nubes, en las únicas partes del techo que sugieren una ilusión espacial. Alrededor, en la cenefa, muchos angelitos acompañan los símbolos de María, así como rodearon a María misma en su Asunción y la veneran en el cielo. Todo se desarrolla en la parte superior del edificio, arriba de pinturas murales que representaban hojas y flores que aluden a la presencia y al florecimiento de la gracia divina en el espacio sagrado de la iglesia.

La iconografía de Santa María responde, por lo tanto, a ideas que sólo pueden entenderse cabalmente dentro de la arquitectura en su totalidad, pero también dentro de un conjunto de imágenes e ideas gestadas desde mucho tiempo antes y desarrolladas a lo largo de siglos, que maduraron en estas formas particulares hacia I 500 y pasaron poco después a la Nueva España. Seguían presentes en Cuevas hacia I700. Y lo mismo puede decirse de elementos importantes del diseño del techo. Al situar el entablado dentro de su tradición formal y estética — de decorar cubiertas de iglesias_-, concluimos que se utilizaron esquemas 
compositivos con raigambre en el siglo XVI en los que había concordancia entre la decoración y el espacio arquitectónico.

Finalmente, entre las conclusiones de este estudio quiero subrayar dos hechos en particular, atestiguados por la decoración de Santa María de Cuevas, y relevantes para la historia del arte novohispano. Uno es que ya había pintores en la Baja Tarahumara por lo menos a partir de finales del siglo XVII. Lo sabíamos por varios documentos, pero en Santa María está la evidencia irrefutable de su presencia in situ. El segundo hecho es que el pintor de Santa María conocía la tradición de decoración mural establecida en el centro del virreinato desde el siglo Xvi. Las pruebas están a la vista. Ambos hechos, además de proporcionar datos antes desconocidos, tienen repercusiones para nuestra manera de entender no sólo el arte de Santa María, de la Nueva Vizcaya y de los jesuitas, sino también el arte del virreinato en general. \$ 